\title{
Fabrication of Implantable Human Arterial Graft by Periodic Hydrostatic Pressure
}

\author{
Junichi Saito, Utako Yokoyama, Toshio Takayama, \\ Hiroaki Ito, Tomomi Tadokoro, Yoshinobu Sugo, \\ Kentaro Kurasawa, Miyuki Ogawa, Etsuko Miyagi, \\ Hideki Taniguchi, Makoto Kaneko, and Yoshihiro Ishikawa
}

\author{
Keywords \\ Tissue engineering - Periodic hydrostatic pressure - Human vascular graft . \\ Implantation · Mechanoresponse
}

Structural heart disease is the most common congenital anomaly, affecting almost $1 \%$ of live births [1]. Approximately $25 \%$ of newborns with congenital heart disease (CHD) require surgical or trans-catheter intervention in the first year of life [2]. Artificial materials such as polytetrafluoroethylene are used for the surgical repair of CHD, but these materials lack growth potential and lead to stenosis according to patient's growth. Therefore, biological tissue-engineered blood vessels are desired for pediatric patients. Recently, we fabricated implantable "scaffold-free" grafts consisting of rat vascular smooth muscle cells by periodic hydrostatic pressure (PHP) [3]. Here we aimed to fabricate implantable human grafts and examine the molecular response to PHP.

\footnotetext{
J. Saito $\cdot$ U. Yokoyama $(\bowtie) \cdot$ Y. Ishikawa $(\bowtie)$

Cardiovascular Research Institute, Yokohama City University, Yokohama, Japan

e-mail: utako@yokohama-cu.ac.jp; yishikaw@med.yokohama-cu.ac.jp

T. Takayama $\cdot$ H. Ito $\cdot$ M. Kaneko

Department of Mechanical Engineering, Osaka University, Suita, Japan

T. Tadokoro $\cdot \mathrm{H}$. Taniguchi

Department of Regenerative Medicine, Yokohama City University, Yokohama, Japan

Y. Sugo $\cdot$ K. Kurasawa $\cdot$ M. Ogawa $\cdot$ E. Miyagi

Department of Obstetrics and Gynecology, Yokohama City University, Yokohama, Japan
} 

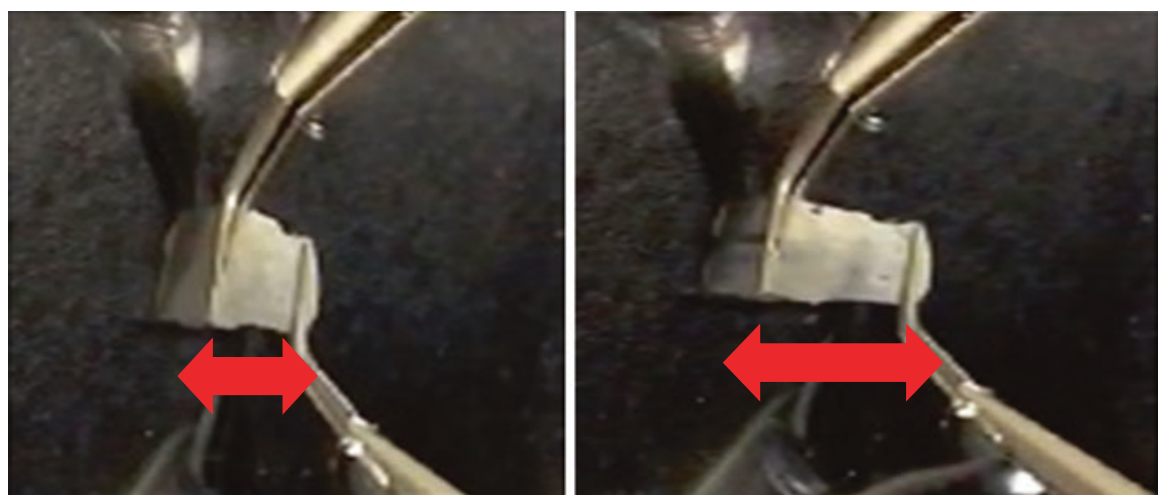

Fig. 46.1 Layered hUASMC showed elasticity

We seeded human umbilical arterial smooth muscle cells (hUASMCs) on a culture disk to make the first cell layer. Twenty-four hours after seeding, cells were exposed to PHP for $24 \mathrm{~h}$, and then cells for the next layer were seeded on the top of the first layer, followed by repeating the same procedure to construct ten layered cell sheets. The multi-layered construct exhibited high elasticity (Fig. 46.1) and was successfully implanted at the aorta of nude rat. Echocardiography confirmed patency, and histological analysis demonstrated complete endothelialization.

We previously demonstrated that PHP promoted actin polymerization and fibronectin fibrillogenesis [3]. We further investigated the molecular response to PHP. hUASMCs were exposed to PHP and subjected to a microarray analysis. A microarray analysis revealed PHP-response genes, which are related to angiogenesis and stabilization of fibronectin. These genes were increased in a pressure-dependent manner, and co-localized with focal adhesion. These mechanoresponse molecules may contribute to construct the multi-layered cell sheets.

Acknowledgment This work was supported by JSPS KAKENHI (U.Y., JP17K19403, JP16H05358; M.K., JP15H05761) and AMED (Y.I., 66890007).

\section{References}

1. Van Der Linde D, Konings EE, Slager MA, et al. Birth prevalence of congenital heart disease worldwide: a systematic review and meta-analysis. J Am Coll Cardiol. 2011;58:2241-7.

2. Simeone RM, Oster ME, Cassell $\mathrm{CH}$, et al. Pediatric inpatient hospital resource use for congenital heart defects. Birth Defects Res A Clin Mol Teratol. 2014;100:934-9433.

3. Yokoyama U, Tonooka Y, Koretake R, et al. Arterial graft with elastic layer structure grown from cells. Sci Rep. 2017;7:140. 
Open Access This chapter is licensed under the terms of the Creative Commons Attribution 4.0 International License (http://creativecommons.org/licenses/by/4.0/), which permits use, sharing, adaptation, distribution and reproduction in any medium or format, as long as you give appropriate credit to the original author(s) and the source, provide a link to the Creative Commons license and indicate if changes were made.

The images or other third party material in this chapter are included in the chapter's Creative Commons license, unless indicated otherwise in a credit line to the material. If material is not included in the chapter's Creative Commons license and your intended use is not permitted by statutory regulation or exceeds the permitted use, you will need to obtain permission directly from the copyright holder. 